\title{
MEMBANGUN RESILIENSI KOLEKTIF MASYARAKAT TRADISIONAL MELALUI PENDIDIKAN MULTIKULTURAL
}

\author{
Ign. Y. Kristio Budiasmoro
}

FKIP Universitas Sanata Dharma Yogyakarta

\begin{abstract}
Traditional peoples order with religiosity and spirituality in harmony with nature, often become vulnerable when the quality and carrying capacity decreases due to the economic exploitation. Diversity of perspectives on the diversity of socio-cultural reality there are many causes for miscommunication and the seeds of social conflict. Conditions of such a society will be increasingly vulnerable in the next collective powerlessness and they will easily become the object of the struggle for economic exploitation. Multicultural education plays an important role in the community to raise awareness of the importance of seeking equality of access rights to live more dignifiedly. Strengthening and revealing of traditional culture values would enhance the collective resilience. The implementation of multicultural education and ethnic identity are expected to become increasingly affirmed. Thus multicultural education is able to contribute to society's in awareness of equality and rights to live more dignifiedly.
\end{abstract}

Keywords: collective resilience, multicultural education, ethnic identity 


\section{PENDAHULUAN}

Masyarakat Indonesia yang memiliki keragaman religi dan budaya selalu memiliki potensi dan peluang besar untuk menggerakkan dialog kebudayaan yang membawa kearah terbukanya wawasan terhadap pemahaman multikultural. Potensi keragaman tersebut tercermin dari fakta bahwa terdapat 360 etnik dengan mayoritas $40 \%$ Jawa dan ratusan kelompok etnik minoritas antara 3-4\%, terdapat lebih dari 700 bahasa lokal dan sebaran pemeluk agama dengan mayoritas Islam sekitar $88 \%$, Kristen dan Katolik $10 \%$, Budha $1 \%$ dan selebihnya penganut Khonghucu dan kelompok agama minoritas lainnya (Kustini, 2008). Pemahaman terhadap prinsip-prinsip multikultural tidak cukup dimaknai sebagai bentuk kesadaran akan keragaman dalam realitas sosial, namun harus sampai pada partisipasi aktif komponen masyarakat dalam membangun kemartabatan yang mengupayakan pemberdayaan, kesetaraan dan toleransi.

Kelestarian kekayaan multietnik masyarakat Indonesia hingga sekarang, telah mengisyaratkan bahwa bangsa Indonesia masih banyak menggunakan bentuk tatanan masyarakat tradisional dalam kehidupan seharihari. Salah satu cirinya yaitu masih tumbuh dan berkembangnya kearifan lokal yang berupa sikap, pandangan dan kemampuan masyarakat dalam suatu wilayah tempat mereka tinggal, yang diyakini dan terus dilestarikan sebagai tradisi kebaikan. Hubungan harmonis antara kehidupan dan pengelolaan lingkungan hidup mereka, menghasilkan keanekaragaman religi sebagai bentuk spiritualitas mereka hidup bersama alam. Keanekaragaman religi masyarakat Indonesia secara historis dibangun oleh interaksi spiritualitas yang tercermin dalam ritual tradisi yang dekat dengan alam dan akulturasi pelaksanaan ajaran-ajaran agama. Kelompok masyarakat yang masih memegang erat tradisi dengan meletakkan spiritualitasnya pada simbol kekuatan alam, sering menggunakan bentuk akulturasi ritual keagaaman untuk menunjukkan eksistensi mereka agar dapat mengikuti perkembangan jaman (Pretty et al., 2008). Kenyataan bahwa daya dukung lingkungan fisik yang semakin menurun akibat kegiatan eksploitasi ekonomi industri, menjadi salah satu penyebab terjadinya perubahan kultur masyarakat tradisional dengan masuknya tatatanan baru yang terkadang tidak mudah dipahami. Kohesi sosial yang merenggang diantara mereka juga sering terjadi akibat hadirnya kepentingan luar yang mengikuti pertumbuhan pusat-pusat ekonomi baru ini. Perubahan sosio-ekologis ini yang membawa kerentanan masyarakat pada situasi yang secara emosional mudah tersulut untuk menjadi sebuah konflik.

Semakin berkembangnya pendidikan dan pengetahuan serta intensifnya interaksi masyarakat antar wilayah pulau-pulau di Indonesia, telah menghasilkan aneka cara pandang masyarakat terhadap pentingnya menggerakkan keragaman sosio-kultur sebagai modal hidup untuk lebih maju. Pemahaman tentang keragaman sosio-kultur masyarakat Indonesia, masih belum dapat menggerakkan modal budaya untuk membangun kemartabatan dan kesejahteraan bersama. Terdapat tiga cara pandang yang masih belum tepat terhadap pemaknaan keragaman sebagai modal budaya yaitu: (1) pemahaman keraga-man yang diwarnai oleh semangat religius dan bukan sosio-kultural, (2) adanya keragaman religi dan budaya yang dimanfaatkan sebagai alasan untuk melakukan pencampuran antara ajaran agama dengan tradisi ritual dalam suatu kelompok masyarakat, dan (3) adanya keragaman religi dan budaya yang dimanfaatkan sebagai alasan untuk terjadinya asimilasi dari tradisi dan religi yang satu menyesuaikan dengan yang lain. Hal ini semakin bias saat salah satu kelompok masyarakat merasa lebih dominan memandang yang lain atau sebaliknya. Ketiga cara pandang ini yang sering menimbulkan ketegangan dalam menterjemahkan keragaman sosio-kultur sebagai modal yang melibatkan partisipasi aktif setiap entitas untuk mewujudkan kesejahteraan dan kemartabatan secara bersama.

Ketegangan semacam ini akan berwujud menjadi konflik-konflik sosial yang masif saat kepentingan kekuasaan, politik dan atau ekonomi terlibat didalamnya. Ketiga cara pandang diatas sering pula dimanfaatkan untuk memarginalisasi kelompok-kelompok masyarakat minoritas yang pada umumnya tingkat pendidikannya masih rendah.

Daya resiliensi masyarakat yang demikian ini akan terus menjadi lemah. Kelompok masyarakat semacam ini akan semakin rentan dalam ketidakberdayaan kolektif yang pada gilirannya akan dengan mudah menjadi obyek perebutan kepentingan kekuasaan kelompok 
politik tertentu atau kelompok usaha tertentu dalam memperebutkan sumberdaya hidup diwilayah mereka. Maka membangun resiliensi melalui pendidikan multikultural dipandang dapat menjadi salah satu aspek penting yang harus dikembangkan dalam pendidikan terutama untuk daerah-daerah pinggiran dan masyarakatnya masih tradisional (Benard, 2002).

Keragaman budaya yang dihargai dan dikelola sebenarnya mampu meningkatkan resiliensi kolektif dari suatu sistem sosial. Mengangkat kembali pengetahuan lokal, nilainilai hidup, norma, keyakinan dan identitas budaya, serta pengembangan sistem interaksi sosial dapat meningkatkan keberlangsungan hidup masyarakat tradisional (Pretty et al., 2008). Mengelola kekayaan dari keanekaragaman budaya untuk sebuah masa depan akan meningkatkan kapasitas sumber daya manusia untuk terus mampu beradaptasi dengan perubahan sistem sosial dan lingkungannya secara cepat (Maffi, 1998; Gunderson \& Holling, 2002).

\section{Resiliensi Kolektif Masyarakat Tradisional}

Resiliensi kolektif merupakan gagasan tentang bagaimana ketahanan masyarakat dalam menghadapi tekanan dan tantangan hidup melalui pengembalian fungsi relasi sosialnya (Kirmayer et al., 2009). Resiliensi sendiri banyak digunakan dalam istilah ekologi dan psikologi untuk menggambarkan carring capacity dan kemampuan untuk mengatasi diri dari tekanan dan stress. Seperti halnya individu, masyarakat juga memiliki kekuatan dan kelemahan dalam mengatasi permasalahan hidup dan mengusahakan keberlanjutan hidupnya. Pengaruh faktor ekonomi sangat berperan besar dalam menentukan daya kebertahanan atau resiliensi suatu kelompok masyarakat. Dukungan berupa sumber daya sosial, budaya dan lingkungan dapat dikembangkan dalam bentuk jejaring sosial yang diperkuat sebagai sistem penyangga kehidupan komunitas. Mengembangkan program pendidikan multikultur untuk anak; mempromosikan kegiatan untuk penyadaran di tingkat keluarga terhadap nilai-nilai budaya, lingkungan dan keragaman; dan mengembangkan jejaring sosial yang peduli dengan layanan pendidikan anak baik disekolah maupun diluar sekolah, merupakan langkah-langkah strategis dalam menganti- sipasi perubahan-perubahan sosial (Kirmayer et al., 2009).

\section{Prinsip-Prinsip dalam Pendidikan Multikultural}

Pendidikan multikultural memegang peran penting untuk menumbuhkan kesadaran bagi masyarakat akan pentingnya mengupayakan kesetaraan terhadap akses hak-hak hidup yang semakin bermartabat. Pendidikan multikultural merupakan gagasan yang mengupayakan agar anak didik mendapatkan kesempatan yang sama dalam berprestasi secara akademik dengan penekanan pada aspek vitalitas keragaman etnik dan budaya dalam membentuk kehidupan yang mengedepankan prinsipprinsip kesetaraan, saling menghormati, dan berkomitmen secara moral untuk mewujudkan terciptanya keadilan sosial (Banks \& Banks, 1993; Baptiste, 1979). Dalam proses mengembangkan resiliensi kolektif masyarakat, pendidikan anak sebagai aset produktif menempati posisi penting. Melalui pendidikan anak akan terbentuk kebiasaan anak menghargai prestasi dan kerja keras (Masten, 2002). Perlu kiranya dalam pendidikan multikultural terutama bagi masyarakat tradisional yang hidup jauh dari akses fasilitas pembangunan lebih menekankan pada kesadaran hidup dalam tatanan multikultural. Bangsa Indonesia yang dikenal bertoleransi, suka bergotong royong dan menjalankan dinamika among dan rembug perlu diangkat kembali sebagai nilai-nilai penting dalam pendidikan di masyarakat. Pendidikan multikultur dalam konteks membangun mental resilien warga masyarakat perlu dikembangkan.

Mengembangkan resiliensi kolektif masyarakat tradisional melalui pendidikan multikultural perlu diperhatikan beberapa prinsip berikut: (1) merupakan sebuah proses yang memberdayakan pribadi dalam suatu perubahan sosial melalui pendekatan pedagogi yang humanis, (2) mengedepankan pencarian kebenaran dengan kejujuran dan kebenaran ilmiah untuk memebrikan pengakuan atas kontribusi kelompok-kelompok yang beragam budaya untuk peningkatan mutu secara bersama-sama, dan (3) merupakan sebuah proses yang berkembang secara sistematis, progresif dan berkelanjutan melalui usaha penyedaran secara reflektif atas pengalaman belajar secara empiris tentang keragaman religi dan budaya masyarakat. 
Pendidikan multikultural yang dikembangkan sebagai proses memanusiakan manusia perlu diletakkan sebagai dasar untuk membangun masyarakat menuju budaya modern. Modernisasi yang dikembangkan harus berbasis pada nilai-nilai budaya lokal yang telah disaring dan disesuaikan dengan arus perkembangan pendidikan. Proses modernisasi bukanlah semata-mata proses transformasi yang berlangsung di bidang ekonomi, tetapi juga, dan bahkan terutama adalah proses pembudayaan. Menjadi tantangan yang tidak kecil untuk menjaga agar upaya memajukan masyarakat berjalan serasi dengan kemampuan masyarakat menyerap nilai-nilai baru yang dibutuhkan dan tetap mampu mempertahankan nilai-nilai tradisi yang mencerminkan kepribadian dan jatidiri masyarakat sebagai bentuk ekspresi identitas budaya mereka. Pendidikan sebagai salah satu alternatif solusi dalam melakukan rekonstruksi sosial dari tatanan tradisional menuju masayarakat modern diyakini menjadi jalan 'damai' yang menyentuh perbaikan mutu generasi di masa depan.

\section{Pendidikan Multikultural untuk Membangun Resiliensi Kolektif}

Membangun resiliensi paralel dengan upaya membangun manusia menuju kehidupan yang lebih sehat. Sebagai upaya dinamis di tengah masyarakat, membangun resiliensi menyediakan ruang interaksi antara aspek psikologis manusia dengan lingkungannya (Benard, 2002). Interaksi semacam ini akan mengembalikan dan memperkuat identitas budaya (khususnya bagi masyarakat tradisional). Keterkaitan antara resiliensi masyarakat dan lingkungan alam, bersifat resiprokal untuk kelompok masyarakat tradisional yang masih memiliki kebiasaan mengambil dan meramu dari alam (Agner, 2000). Mem-perkuat resiliensi masyarakat tradisional selalu berfokus pada kehidupan anak-anak, keluarga mereka dan tradisi mereka dalam menjalani hidup sehari-hari yang masih terikat dengan sistem natural lingkugan alam tempat mereka hidup (Masten, 2002).

Penguatan identitas etnik pada pribadipribadi yang berasal dari kelompok masyarakat tradisional yang terpinggirkan menjadi penting untuk menumbuhkan rasa percaya diri dan mengembangkan kesadaran (Banks, 2010). Prinsip-prinsip kurikulum pendidikan multikultur dalam rangka menguatkan identitas etnik menurut National Council for the Social Studies (NCSS) dalam Banks (2002) adalah sebagai berikut:

1. Keragaman etnik dan budaya harus diperkenalkan dan dihargai oleh setiap individu, kelompok (termasuk unsur keluarga) dan masyarakat

2. Keragaman etnik dan budaya harus ditujukan untuk menguatkan, melekatkan dan meningkatkan daya tahan/resiliensi masyarakat

3. Kesetaraan dalam mendapatkan kesempatan (utamanya akses pendidikan dan ekonomi) harus diberikan untuk seluruh golongan dan kelompok etnis

4. Pengenalan identitas etnik dan budaya harus ditunjukkan sebagai pilihan merdeka setiap individu dalam suasana yang demokratis

Sebagai bentuk pelaksanaan dari prinsip-prinsip kurikulum pendidikan multikultur ini digunakan empat pendekatan dalam Banks (2002) dengan penyesuaian kompleksitas permasalahan yang berbeda untuk setiap tingkat pendidikan.

1. Pendekatan kontribusi. Seperti banyak yang sudah dilakukan di sekolah-sekolah, memasukkan cerita dan gambar-gambar kepahlawanan nasional yang berasal dari berbagai daerah di Indonesia. Hal ini ditujukan pada prinsip paling dasar yaitu membangkitkan kebanggaan akan asal etnis peserta didik. Perlu juga dicari cerita-cerita kepahlawanan lokal agar peserta didik mengenali siapa dan bagaimana tradisi ritual termasuk bahasa 'ibu' mereka.

2. Pendekatan aditif. Pada tahap ini penambahan materi, konsep, tema dan perspektif diberlakukan untuk mempertajam kurikulum sekolah tanpa merubah struktur dan substansi kurikulum. Identifikasi nilai-nilai luhur budaya ibu dan budaya lain mulai dimunculkan sebagai aktivitas yang merangsang keluasan wawasan peserta didik.

3. Pendekatan transformatif. Pada tahap ini asumsi dasar kurikulum diubah dan kompetensi atas penguasaan konsep, tema dan permasalahan multikultur mulai ditumbuhkan. Peserta didik diperbolehkan untuk melihat dalam berbagai persepsi 
etnis agar terjadi proses akulturasi pemahaman konsep budaya.

4. Pendekatan aksi sosial. Apa yang sudah dilakukan pada tahap pendekatan transformatif ditambahkan aksi nyata peserta didik dalam mempelajari proses perubahan sosial. Bisa jadi bentuk-bentuk pembelajaran place based learning dan project based learning menjadi salah satu alternatif menarik agar anak mengalami interaksi sosial secara langsung. Dari lapangan mereka merencanakan aksi, emlaporkan dan melakukan refleksi yang kemudian diikuti tindak lanjut bersama komunitas masyarakat diluar pembelajaran

Bentuk pendekatan aksi sosial dalam konteks membangun resiliensi masyarakat tradisional yang terpinggirkan menjadi sangat relevan dan bermanfaat untuk menumbuhkan kohesi sosial melalui pendidikan termasuk meningkatkan tanggung jawab sosial di masyarakat. Muatan pembelajaran tidak hanya masalah tradisi dan identitas etnis namun bisa sangat luas menyentuh kehidupan nyata masyarakat misalnya pembelajaran koperasi, kewirausahaan dan konservasi lingkungan (Sinagatullin, 2003). Masyarakat tradisional biasanya akan mudah belajar dan mempercayai dengan semua bentuk tindakan nyata. Sehingga mereka bisa melihat langsung, merasakan dan ikut terlibat dalam menerjemahkan konsep-konsep pengetahuan dalam pembelajaran. Syarat dukungan dan keterlibatan keluarga, lembaga sosial dan adat, dan bahkan birokrasi pemerintahan desa menjadi bagian dari pelaksanaan pembelajaran.

Pelaksanaan pembelajaran tidak hanya sekedar di sekolah tetapi juga di masyarakat. Menggerakkan orang tua dan lembaga diluar sekolah untuk melaksanakan gerakan masyarakat yang belajar dapat diimplementasikan dalam suatu model yang disebut rumah belajar. Rumah belajar ini konsepnya tidak lain adalah sebuah ruang diskusi publik yang dikelola oleh masyarakat untuk memfasilitasi proses belajar anak setelah berada diluar sekolah, sementara kondisi rumah tidak mendukung atau tidak didukung oleh orang-orang yang ada di dalam rumah. Proses belajar di sekolah perlu didorong kesinambungan belajarnya hingga di rumah. Hal ini sangat membantu anak dalam mengerjakan tugas dan bersosialisasi dengan aneka macam strata sosial dan multietnis masyarakat disekitarnya. Rumah belajar semacam ini dalam beberapa praktik di lapangan mampu menggerakkan proses sosialisasi dengan bagus. Mulai dari anak sekolah, pemuda karang taruna hingga orang tua yang menggunakan fasilitas rumah belajar untuk mendiskusikan kegiatan-kegiatan pembangunan di desa mereka. Rumah belajar menjadi semacam pusat belajar dan perencanaan aneka macam pengembangan kegiatan di masyarakat dari sore hingga malam hari. Dengan strategi ini kepedulian masyarakat terhadap pendidikan dapat didorong perlahan-lahan untuk mau terlibat dan membuat aksi bersama.

Dengan demikian tumbuhnya kesadaran akan modernisasi melalui proses pendidikan multikultural, tidak akan mencerabut mereka dari akar tradisi yang diseleksi dan diperkuat menjadi budaya yang maju terbuka dan demokratis (Zamroni, 2011 a). Dalam rumah belajar terbentuk suatu aktivitas belajar yang mengarah pada gerakan "truth and reconciliation" aneka macam kepentingan dari berbagai pihak yang dulunya sering berseberangan sikap. Mereka membuka tabu permasalahan konflik dan melakukan skrining terhadap kebiasaan dan perilaku yang menjadi penyebab konflik. Mengeliminir aspek pembiasaan negatif dan memperkuat tradisi produktif dan kreatif merupakan salah satu pendekatan sektoral yang dapat digerakkan dalam bidang pendidikan, pengembangan sosial dan perwujudan ekonomi yang berkeadilan diantara mereka. Kondisi semacam ini akan terus menumbuhkan daya resilien dan adanya dukungan pertumbuhan ekonomi kreatif tidak menutup kemungkinan masyarakat tradisional ini mampu bersaing dengan para pendatang di lingkungan mereka. Dengan demikian kelompok masyarakat ini akan menjadi masyarakat yang terbuka pada proses modernisasi dan memiliki posisi tawar yang semakin tinggi. Budaya kreatif dan produktif akan menghasilkan cara pandang baru terhadap eksistensi kultural, nilai-nilai keyakinan masyarakat dan spiritualitas yang akan membawa perubahan sosial melalui sistem ekonomi kreatif (KEA, 2009).

Kondisi menuju masyarakat tradisional yang mendapatkan kembali daya resiliensinya, harus ditopang oleh komitmen pemerintah untuk berpihak pada kelompok yang 
termarginalisasi ini. Seperti yang disebut oleh Bandura (1977) bahwa ada empat sumber daya yang membentuk resiliensi yaitu: (1) pengalaman yang tuntas, (2) pengalaman yang terdampingi, (3) persuasi masyarakat, dan (4) penguasa yang berpihak. Sangat disadari bahwa pendidikan di Indonesia saat ini belum mampu mengatasi masalah disparitas kesejahteraan bahkan semakin menegaskan kemiskinan lintas generasi, seperti diungkapkan dalam Zamroni $\left(2011_{\mathrm{b}}\right)$. Ketidaksetaraan pendidikan merupakan akar dari terbentuknya struktur kelas di masyarakat. Ketidaksetaraan dalam pendidikan ini menegaskan pula sebagai bagian dari masyarakat kapitalis yang memegang prinsip-prinsip meritokrasi dan membuat polarisasi dengan masyarakat tradisional di sisi yang berseberangan (Bowles, 2000). Sebagai bentuk strategi peningkatan mutu, pendidikan anak dan pemberdayaan ekonomi yang terarah pada penciptaan sistem produksi dan konsumsi berkelanjutan (sustainability production and consumption) perlu dikembangkan secara paralel untuk dapat mengangkat kembali resiliensi kelompok masyarakat tradisional yang termarginalisasi.

\section{PENUTUP}

Pendidikan multikultural yang dikembangkan sebagai proses memanusiakan manusia perlu diletakkan sebagai dasar untuk membangun masyarakat menuju budaya modern. Modernisasi yang dikembangkan harus berbasis nilai-nilai budaya lokal yang telah disaring dan disesuaikan dengan perkembangan pendidikan dunia. Identitas etnis dan entitasnya menjadi semakin terafirmasi dan dapat dimaknai sebagai modal budaya untuk memacu ketertinggalan dalam gerak langkah modernisasi. Dengan demikian pendidikan multikultural mampu memberi kontribusi pada masyarakat berupa kesadaran akan pentingnya kesetaraan dan kesadaran hak-hak hidup yang semakin bermartabat serta kebersamaan untuk mewujudkan kehidupan yang lebih baik.

\section{DAFTAR PUSTAKA}

Adger, WN. (2000). Social and ecological resilience: Are they related?, Prog. Hum.Geogr 2000 24: 347-364
Bandura, A. (1977). Self efficacy: Toward a unifying theory of behavioral change. Psychological Review, 84, 191-215

Banks, J.A.. 2002). An introduction to multicultural education, $3^{\text {rd }}$ ed., A Person Education Company, Boston, pp: 30,114

(2010). Multicultural Education: Characteristics and Goals, dalam Banks J.A., and Banks CA, (Eds.) Multicultural Education Issues and Perspectives, $7^{\text {th }}$ Ed., John Wiley and Sons Inc., pp:13-15

Banks, J.A. \& Banks, C.A.M. (1993). Multicultural education: Issues and perspectives (2nd ed.). Boston: Allyn and Bacon.

Baptiste, H.P. (1979). Multicultural education: A Synopsis. Washington, D.C.: University Press of America

Benard, B., 2002, Aplication of resilience: posibilities and promise, dalam Glantz MD and JL. Johnson (Ed), Resilience and Development, Positive Life Adaptation. Kluwer Academic Pub., pp: 269-276

Blackburn, R. (2007). 'A global pension plan', New Left Review, vol 47, September-October, p:71

Bowles, S., (2000). Unequal education and the reproduction of the social division of labor, in Noel J. (Ed), Sources: Noteable Selections in Multicultural Education, McGraw-Hill, Connecticut, pp:47-53

Ferguson, A.R.B. (2005). The roots of delusion. Population Press, Summer/ Fall 2005, 11(2): 29-30. Diambil pada tanggal 15 Desember 2011, dari http://www.popco.org/press/articles/20 05-11-ferguson.html.

Gunderson, L.H. and C.S. Holling. (2002). Panarchy: Understanding transformations in human and natural systems. Island Press, Washington, DC

KEA. (2009). The impact of culture on creativity. Tidak diterbitkan. European Commission (Directorate-General for Education and Culture). 
Kirmayer L.J., Sehdev M., Withley R., Dandeneau S.F., \& C. Issac. (2009). Community resilience: Models, Metaphors and Measures, Journal of Aboriginal Health, November.

Kustini. (2008). Tradisi, modernisasi dan keharmonisan umat beragama. Jurnal Multikultural dan Multireligius. Vol. VII No.27, hal:6-7

Maffi, L. (1998). Language: A resource for nature. Nature and Resources: The UNESCO Journal on the Environment and Natural Resources Research 34(4): 12-21

Masten, A.S. (2002). Resilience come of age, reflection on the past and outlook for next generation of research, dalam Glantz MD and JL. Johnson (Eds), Resilience and Development, Positive Life Adaptation. Kluwer Academic Pub., pp: 281-296

Pretty J., Adams B., Berkes F., de Athayde S.F., Dudley N., Hunn N., Maffi L., Milton K., Rapport D., Robbins P., Samson C., Sterling E., Stolton S.,
Takeuchi S., Tsing A., Vintinner E., \& S. Pilgrim, 2008, How Do Biodiversity and Culture Intersect?, Plenary paper for Conference "Sustaining Cultural and Biological Diversity In a Rapidly Changing World: Lessons for Global Policy". Organized by American Museum of Natural History's Center for Biodiversity and Conservation, IUCN-The World Conservation Union/Theme on Culture and Conservation, and Terralingua. April 25th 2008

Sinagatulin, I.M., (2003). Constructing Multicultural Education in a Diverse Society, The Scarecrow Press, Inc. London, pp: 88-96

Zamroni. (2011a), Pendidikan Demokrasi pada Masyarakat Multikultural, Gavin Kalam Utama, Yogyakarta, hal: 33,114115

(2011b), Dinamika Peningkatan Mutu, Gavin Kalam Utama, Yogyakarta, hal: 58-59; 299-300 